\title{
Tube Expansion Under Various Down-Hole End Conditions
}

\author{
FJ Sanchez and OS Al-Abri*b
}

\author{
${ }^{a}$ Well Engineering Directorate, New Technology, Petroleum Development Oman, Muscat, Sultanate of Oman \\ ${ }^{b}$ Department of Mechanical and Industrial Engineering, College of Engineering, Sultan Qaboos \\ University, Al-Khoud, Muscat, Sultanate of Oman
}

Received 19 May 2012; accepted 27 November 2012

\begin{abstract}
Fossil hydrocarbons are indispensables commodities that motorize the global economy, and oil and gas are two of those conventional fuels that have been extracted and processed for over a century. During last decade, operators face challenges discovering and developing reservoirs commonly found up to several kilometers underground, for which advanced technologies are developed through different research programs. In order to optimize the current processes to drill and construct oil/gas wells, a large number of mechanical technologies discovered centuries ago by diverse sectors are implemented by well engineers. In petroleum industry, the ancient tube forming manufacturing process founds an application once well engineers intend to produce from reservoirs that cannot be reached unless previous and shallower troublesome formations are isolated. Solid expandable tubular is, for instance, one of those technologies developed to mitigate drilling problems and optimize the well delivery process. It consists of in-situ expansion of a steel-based tube that is attained by pushing/pulling a solid mandrel, which permanently enlarge its diameters. This non-linear expansion process is strongly affected by the material properties of the tubular, its geometry, and the pipe/mandrel contact surface. The anticipated force required to deform long sections of the pipe in an uncontrollable expansion environment, might jeopardize mechanical properties of the pipe and the well structural integrity. Scientific-based solutions, that depend on sound theoretical formulation and are validated through experiments, will help to understand possible tubular failure mechanisms during its operational life. This work is aimed to study the effect of different loading/boundary conditions on mechanical/physical properties of the pipe after expansion. First, full-scale experiments were conducted to evaluate the geometrical and behavioral changes. Second, simulation of deformation process was done using finite element method and validated against experimental results to assess the effects on the post-expansion tubular properties. Finally, the authors bring a comparison study where in a semi-analytical model is used to predict the force required for expansion.
\end{abstract}

Keywords: Tube expansion, Solid Expandable Tubular (SET) technology, FEA, Casing, On- and Off-Shore

$$
\text { تأثير وضعية طرفي الأنبوب على عملية تمديد الأنابيب في الآبار }
$$

$$
\begin{aligned}
& \text { الملخص: يعد النفط والغاز أحد أبرز المشتقات الهيدروكربونية التي تحرك الاقتصاد العالمي والتي يتم استخر اجها ومعالجتها لأكثر من قرن. ولكن خلال }
\end{aligned}
$$

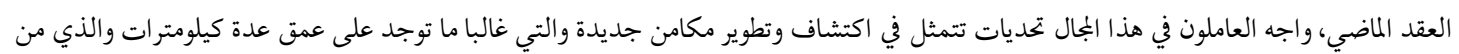

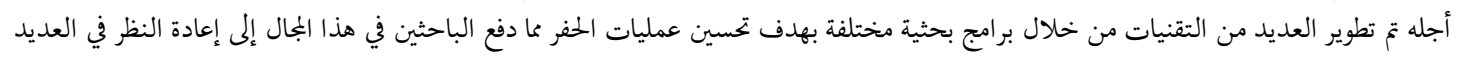

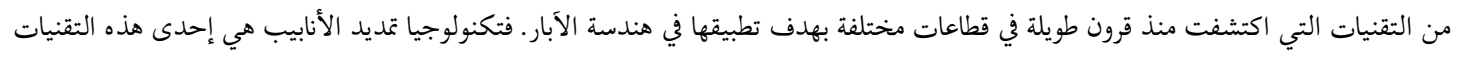

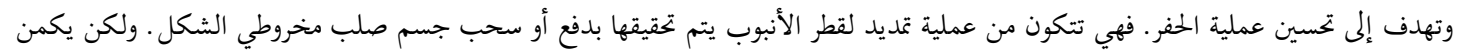

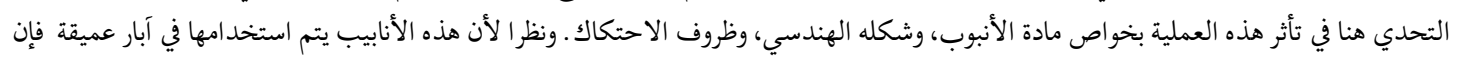

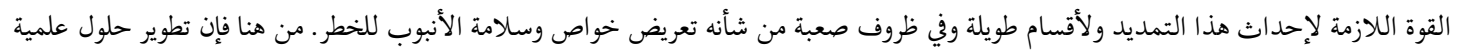

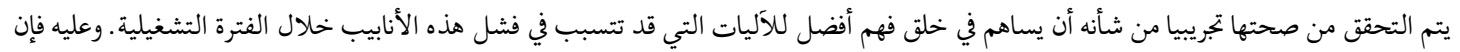

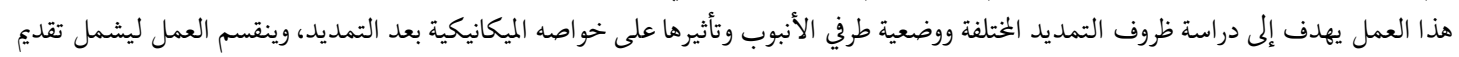

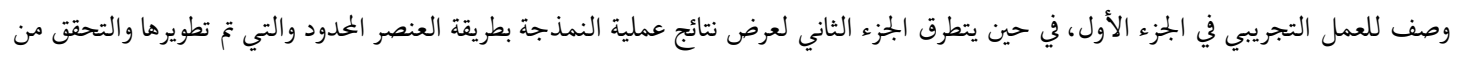

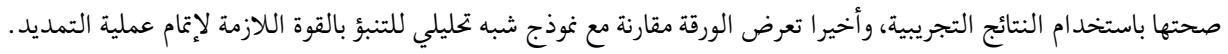

$$
\begin{aligned}
& \text { المفردات المفتاحية: تمديد الأنابيب، تكنولوجيا تمديد الأنابيب الصلبة، طريقة العنصر المحدود، أنبوب، على اليابسة وفي البحر. }
\end{aligned}
$$

$\overline{\text { *Corresponding author's e-mail: m053898@squ.edu.om }}$ 


\section{Introduction}

Liquid and gaseous fossil hydrocarbons have recently been extracted from much deeper reservoirs localized in areas surrounded by uncertain, challenging environments such as deep water, off-shore applications. Deep reservoirs are difficult to reach not only because of the depth and the overburdening pressure acting on previous geological formations above the hydrocarbon-source rock, but also because of the instability of shallower, less compact formations within the first few hundred meters from the surface of the earth. Those unconsolidated, lower pressure formations must be isolated in order to reach the desirable oil/gas reserves; and that is accomplished by drilling wells in a telescope manner. In other words, starting the drilling process from the earth's surface with a large sized hole, the reservoir is finally reached with a much slimmer hole size and pipes, for which well engineers drill necessary sections in between to install steel-based pipes and, consequently, to cement it in place. This telescoping approach drives the casing design since the first oil/gas well was drilled (Cales 2003). The configuration of those sections varies depending upon the characteristics of the field-vertical, deviated, or horizontal-the three possible well geometries.

Other reservoirs from which the extraction of oil and gas has deserved more attention during the last decade are less profound and require unconventional methods of drilling and production. However, the wells are drilled, completed, and potentially repaired by using the same conventional rules of casing design: a smaller size casing string is installed deeper and through the previous larger size string. From researchers and engineers to business improvement and operational managers, to optimize the economics of well delivery and field development by implementing either conventional or unconventional drilling or work-over approaches is a continual challenge. Addressing those challenges with a feasible technology already implemented in more than 400 wells and with a proven track record since the late 1990s has been a major accomplishment in the oil and gas industry. Solid expandable tubular (SET) technology not only optimizes the telescoping casing design approach in existing wells but also can reduce its own effect by installing multiple casing strings and preserve the desirable monobore hole size from the surface to the reservoir's depths.

Reliable mechanical and physical properties of a SET after its expansion in the wellbore are, in some cases, not clearly understood by the majority of well engineers and designers. The technology has been concealed by a minority of service companies which assert that it could be considered suitable for low risk wells as well as high pressure and high temperature wells. This document summarizes the results obtained from several simulations using finite element model and physical tests run on pipes. The research was mainly focused on the expansion effect on physical dimensions and the possible contribution towards the post-expansion mechanical properties of tubular samples, which were plastically deformed by using a state of the art test rig.

\section{Solid Expandable Technology}

Since the late 1990s, oil and gas companies have implemented an alternative technology to effectively overcome wellbore problems during drilling, completion, and repairing (work-over) operations. SET technology has been implemented in a myriad number of situations since its first installation, with the intention to reduce operational costs and optimize the well delivery process not only as part of a contingency plan, but also as a fundamental component of the original drilling program. SET technology is currently known as a value-added, fit-for-purpose, and enabling alternative towards an effective drilling campaign (Dupal et al. 2002; Carstens and Scrittmatter 2006).

Even though several published papers and articles have already described the concept, functionality, and benefits of SET in a countless number of cases, the authors decided to describe the technology using a basic approach. In other words, the key idea behind SET technology is based on the fact that it is based on a down-hole in situ expansion of the pipe's inner diameter that is attained by hydraulic and/or mechanical forces. An internal mechanism that is capable of either pulling or pushing a solid, high-strength mandrel from the bottom upwards permanently deforms the tubular to the required size (Fig. 1). Many designs and processes have been created over the years to come up with a suitable SET technology for exclusive applications, and one of those is the mono-diameter well (Jabs 2004), as opposed to the standard practice of the telescopic casing design approach. Reducing the telescopic nature of conventional wells would allow a much smaller surface casing to be used, and consequently the subsequent casings could be reduced in diameter. Additionally, with the aid of the SET technology, operators will be able to reduce the resources required per drilling campaign, as well as reaching target depths with a greater diameter to improve the overall oil/gas production (Campo et al. 2003).

Although it has gained wide acceptance within the industry, expandable tubing technology still requires massive engineering research and development tests before it can be used to its full potential. Its ease of use in the down-hole environment will only be possible by 


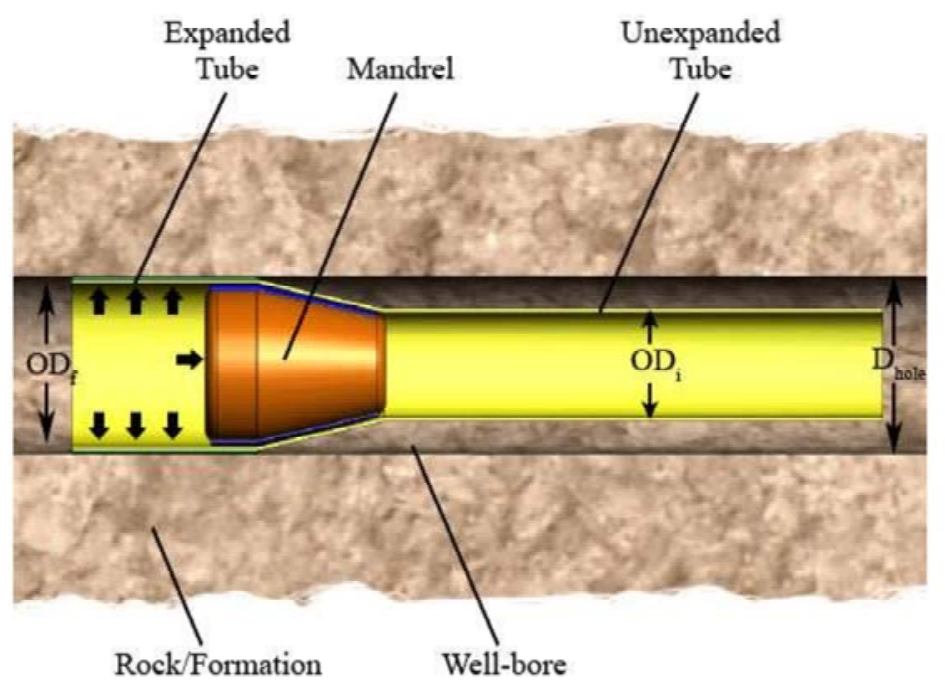

Figure 1. Schematic diagram of tubular expansion process using conical mandrel

properly understanding geometric and contact non-linearities, dynamics of components/system involved in the expansion process, and post-expansion material and mechanical properties of the tubular. The data generated through those tests will assist researchers in developing improving techniques, tools, procedures, and materials which can attain higher expansion percentages while maintaining the post-expansion tubular strength required by design and well engineers. This may reduce the cost of expandable tubular pipes and open a new horizon of applications away from the oil and gas well construction industry.

A review of selected literature on down-hole tubular expansion (Cales et al. 2001; Dupal et al. 2002; Mack 2005; Carstens and Scrittmatter 2006; Binggui et al. 2009) shows that most of the research and development work was carried out mainly by technology deployment companies to find short term and problem specific solutions. The experience of field engineers and a few simple lab trials were mainly instrumental in devising solutions without having substantial theoretical basis and appropriate scientific validation. The pioneering work of (Filippov et al. 1999) presented three feasible scenarios of SET technology including openhole liner, cased-hole liner, and expandable liner hanger systems. Mack et al. (1999) identified the chemical composition of expandable steel tube of grade L-80, and conducted an experimental study to determine the effect of expansion on its mechanical properties. Other authors, on the other hand, like (Stewart et al. 1999; Karrech and Seibi 2010) developed a simplified mathematical model that describes the effect of tubular expansion on its burst strength, and an analytical model for the tubular expansion process in which the stress field in the expansion zone, expansion force, and dissipated energy were predicted in order optimize the mandrel shape, respectively.

More recently, Akisanya et al. (2011) used elastic- ity and plasticity theories to develop a model relating the hydraulic pressure, geometric dimensions of tubulars and the residual contact pressure between two concentric pipes in a typical hydraulic forming process. An important aspect, which was inadequately addressed in developing in situ tubular expansion, is the post-expansion characterization of the tube. The reliability and structural integrity of tubular pipes during their life spans are equally important, because most well engineers are principally interested in the mechanical strength of the post-expansion casing, which must withstand all loads generated either by the formation or by the drilling operation itself. Further to this, very limited research work has been done on developing analytical and simulation models of the tubular expansion process, including inherent non-linearities, its dynamics, the effect of the interaction between mandrels and pipes and/or pipe and formation interfaces, and contact with surrounding fluids.

The current research on SET technology started in the early 2000s, with the main supporter being the oil company. More recently the interest of other entities has been drawn. Oil companies' well engineers, along with others, require the know-how to best adopt SET technology during drilling and remediation campaigns. The goal of using effective SETs is to enhance oil and gas recovery, improve well delivery time, and optimize the overall cost of the drilling process. In this context, research has focused upon developing semianalytical and finite element models in the early stages. However, the capacity of the research has been strengthened with the incorporation of the Expandable Tubular Test-Rig at SQU, which is capable of generating the forces needed during the installation of SETs and simulate precisely the expansion of the pipe. In order to describe the capability of such a facility, the authors would like to highlight all the research activities conducted at Sultan Qaboos University (SQU), 
which has tackled many essential SET-related topics, including

* The simulation of tubular expansion using the finite element method to study the effects of different expansion ratios, friction coefficients and mandrel angles on the tubular expansion process (Pervez et al. 2005);

* A simplified mathematical model for tubular expansion process (Seibi et al. 2005);

* An analytical solution for wave propagation due to the pop-out phenomenon (Seibi et al. 2006; Pervez et al. 2006);

* Post-expansion tube response under mechanical and hydraulic expansion-A comparative study (Seibi et al. 2007);

* Research on the possibility of using aluminum in expandable tubular technology instead of steel (Pervez et al. 2008);

* The dynamic effects of mandrel-tubular interaction in the down-hole tubular expansion process (Seibi et al. 2009);

* An experimental and numerical investigation of expandable tubular structural integrity for well applications (Pervez 2010; Pervez et al. 2012);

* The simulation of tubular expansion in irregularly shaped boreholes (Pervez et al. 2011), and

* Finite element analysis of tubular ovality in oil wells (Pervez and Qamar 2011).

An important issue which still has not been addressed in the available literature on SET technology is the effect of loading/boundary conditions on tubular structural integrity and its mechanical properties. These conditions sometimes have resulted in undesirable geometrical and behavioral changes in the pipe during the expansion process which may lead to premature failure of the SET during its lifetime. A close look at the expansion process, supported by experimental data, showed that these failures may occur due to unfavorable thickness variations during the expansion process.

In view of the discussion above, the objective of this work was to conduct a study to investigate the effect of different loading/boundary conditions on the force required for expansion as well as on tubular structural integrity after expansion, including the pipe's length and thickness variations. However, based on the fact that the tubular expansion process is highly non-linear and includes many complicated scenarios, the task of obtaining inclusive and accurate closed-form solutions is very challenging. Thus, experimental and finite element techniques need to be adopted to determine the effect of different loading/boundary conditions. A comparative study between experimental, finite element and/or semi-analytical results of post-expansion characteristics in expandable piping will be presented, and an appropriate conclusion will be inferred.

\section{Experimental Study}

Experimental tests of tubular expansion processes were conducted using an expandable tubular test-rig to study the effect of different loading/boundary conditions. The test-rig, built in the Engineering Research Laboratory (ERL) at SQU (Fig. 2) is one of the few facilities of its kind in the world, and the first in the Gulf region. In terms of capacity, the mechanical structure is capable of expanding tubular sizes ranging from $2.7 / 8$ of an inch $(73.025 \mathrm{~mm})$ to $9.5 / 8$ of an inch $(244.475 \mathrm{~mm})$, with expansion percentages varying from $10-30 \%$ based on inner diameter of the tubular. Furthermore, the test-rig is capable of testing pipes of lengths varying from 2-10 meters, and under fixedfree and fixed-fixed end conditions. The facility includes high-pressure/high-flow hydraulic pumps capable of supplying 2350 bars (34075 psi) at 11 liters/minute or 700 bars $(10150$ psi $)$ at 50 liters/minute. In order to simulate the commonly used tubular expansion approach of cone-on-stick (ie. mechanical expansion), the test-rig is provided with a hydraulic cylinder that is capable of delivering an expansion force of up to 140 metric-tons.

During the research, the tests were performed on standard SETs utilized by oil/gas well applications using conventional-sized mandrels but under different loading/boundary conditions, as shown in Table 1 . Figure 3 summarizes the procedure adopted to prepare the tubular specimens for the experimental expansion tests. First, the mandrel was entered into a small tubular segment by means of a mechanical pressing machine (Fig. 3(a)). This combined part becomes a canister, commonly known by SET operators as a launcher. The side of the launcher was then welded into a longer to-be-expanded tubular segment (Fig. 3(b)) while the other was welded to a flange (Fig. $3(\mathrm{c})$ ), producing a small chamber behind the mandrel that was used to accumulate the hydraulic pressure in order to push the mandrel forward. In order to ensure perfect alignment of the mandrel during the expansion process, a fit-for-purpose aligner was used, made of two separated discs with diameters equal to the nominal drift diameter of the tubular pipe. Then the tubularmandrel system was mounted on the test-rig (Fig. 3(d)) and, afterwards, the high pressure flow-line was connected to the flange in order to supply the hydraulic fluid required to push the mandrel forward (Fig. 3(e)). A view of the experimental setup just before the start of the test is shown in Fig. 3(f).

In down-hole applications, the pipe is usually run through an existing casing string and deployed to a specific depth with the mandrel attached to it. Once the system is positioned in an open-hole or inside pre- 


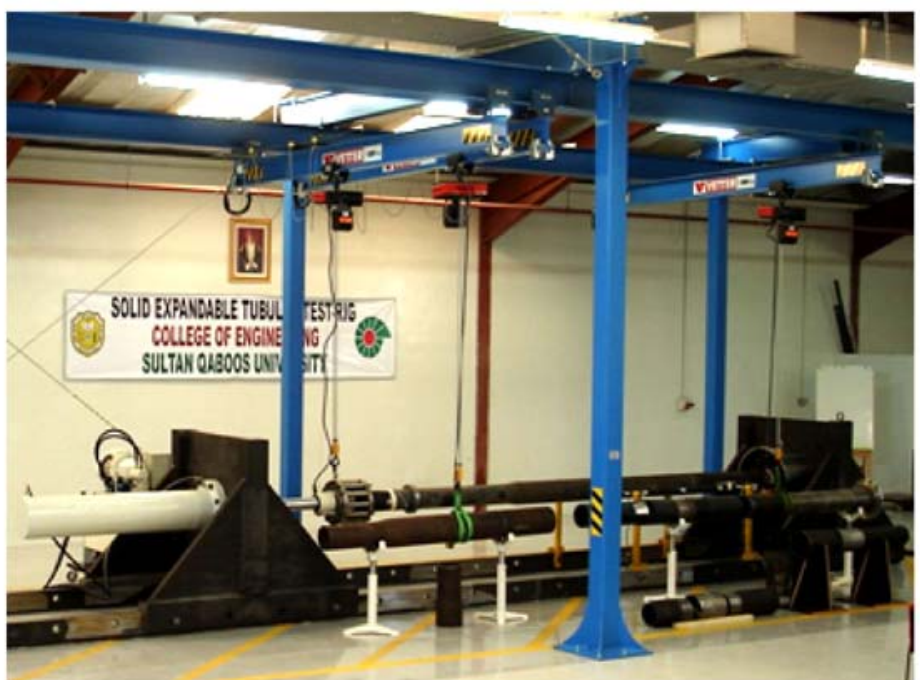

Figure 2. The Expandable Test Rig (ETR) at the Engineering Research Lab (ERL) at Sultan Qaboos University

Table 1. Tubular and mandrel sizes used during the experimental test

\begin{tabular}{ccccc}
\hline Component & $\begin{array}{c}\text { Sample } \\
\text { Outer Diameter } \\
\text { (OD) } \mathrm{mm}\end{array}$ & $\begin{array}{c}\text { Wall Thickness } \\
\text { (t) } \mathrm{mm}\end{array}$ & OD/t Ratio \\
\hline Solid Expandable & (a) & 193.68 & 9.53 & 20.32 \\
Tubular(SET) & (b) & 203.20 & 10.16 & 20.00 \\
& (c) & 203.20 & 12.70 & 16.00 \\
\hline & $(1)$ & 203.20 & N/A & N/A \\
Mandrel Size & $(2)$ & 209.55 & N/A & N/A \\
& $(3)$ & 215.90 & N/A & N/A \\
& $(4)$ & 218.44 & N/A & N/A
\end{tabular}

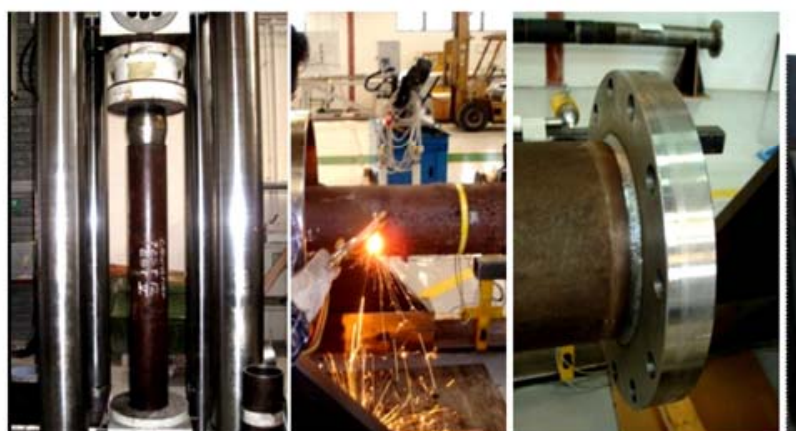

(a)

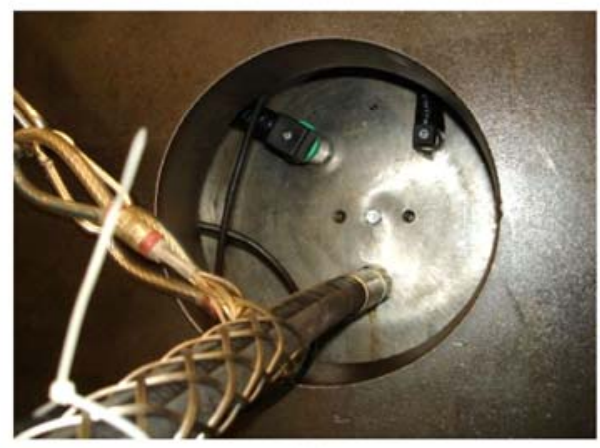

(e)

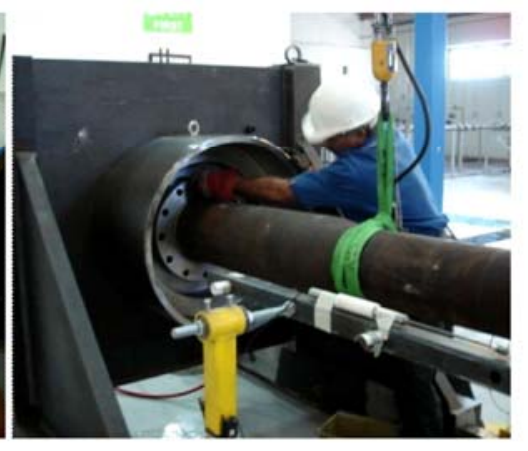

(d)

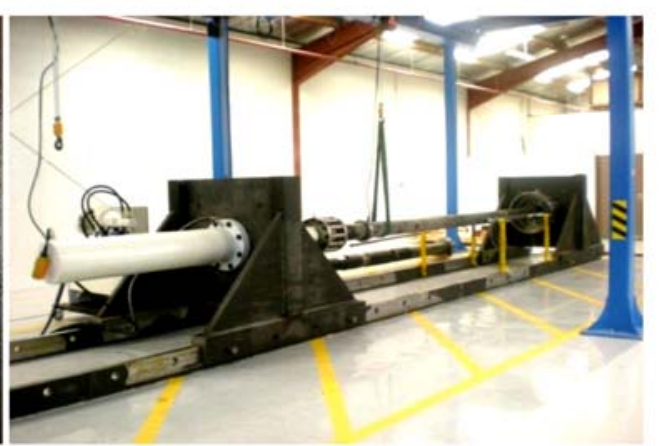

(f)

Figure 3. Experimental test set-up procedure: (a) Create launcher using mechanical pressing machine; (b) Welding launcher to longer pipe section; (c) Flange welded to the launcher; (d) Mounting tabularmandrel system in the rest-rig; (e) High pressure line connected to the flange; (f) Pipe ready for test 


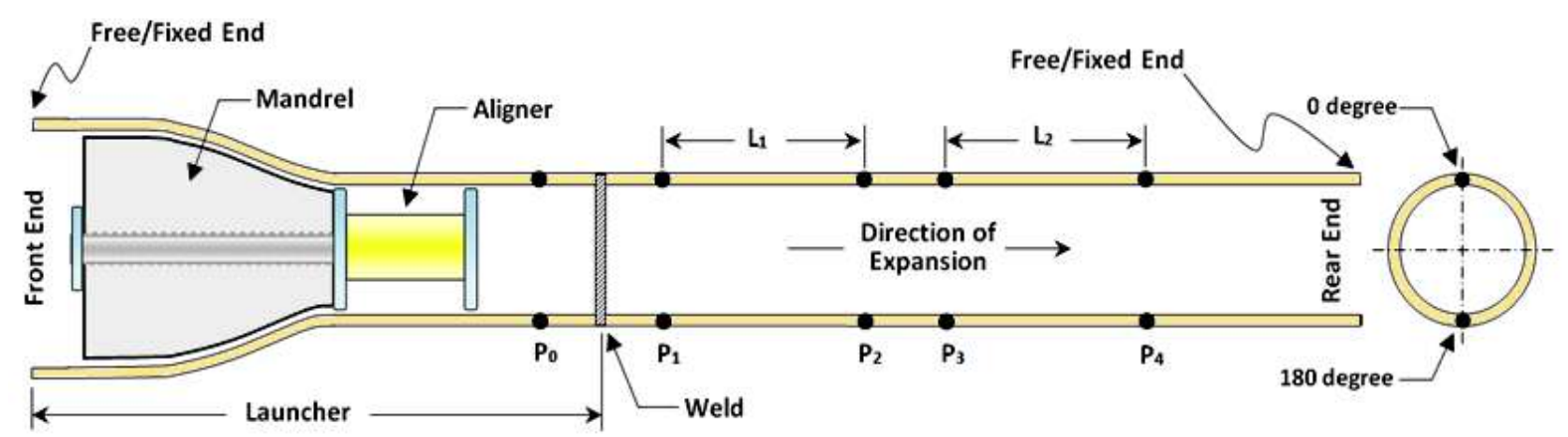

Figure 4. Schematic diagram of the expandable tubular test setup

vious casing, it is anchored in place by fixing one of its ends. The anchoring is usually done against the formation in open-hole applications such as expandable open-hole liners (Carstens and Scrittmatter 2006; Dupal et al. 2002) or against another tubular in casedhole applications such as expandable casing clads (Bin Ali et al. 2009). Afterwards, the expansion process was executed.

Based on whether the bottom section (front-end in Fig. 4), the top section (rear-end in Fig. 4), or both of them happened to be fixed during conventional tubular expansion applications, the expansion process may enter into many scenarios. The pipe is expanded under (a) tension when the bottom section (front end) is fixed and the top section (rear end) is free, and (b) compression when the front end is free while the rear end is fixed. A unitized expansion-condition is present when one of the ends is fixed but the other one also gets unintentionally stuck during the setting process; in this special case, the SET is expanded under a fixed-fixed condition and combined stress loads. Further to this, based on whether the expansion process is performed hydraulically or mechanically, another two scenarios might result.

The current work investigates the difference in the effect between the mechanical and hydraulic expansion processes along with the effect of different loading/boundary conditions on the structural integrity of the tube. However, since the testing procedure is cumbersome and usually requires careful selection of tools and procedures, only some of these cases have been tested experimentally based on which analytical and/or finite element solutions have been obtained, validated, and employed for further investigation.

In order to obtain necessary data to perform the experiment, the test-rig is provided with proper instrumentation to monitor, control, and store information related to principal variables. The mechanical and hydraulic parameters recorded during the test include strain, diametrical displacement, expansion force, wall thickness and length variations, operating fluid temperature, flow rate, and the speed and location of the expansion mandrel. Several electronic pressure sen- sors were used to measure the hydraulic pressure supplied to the mandrel-tubular system, and an ultrasonic sensor was employed to monitor the mandrel position as it moved along the pipe during the expansion process. The variation in outside diameter was precisely measured through a linear voltage displacement transducer (LVDT), which was selectively installed on opposing sides of the pipe $\left(0-180^{\circ}\right)$. The variation in pre- and post-expansion wall thickness was measured by using a TI-25DL ultrasonic wall thickness gauge at five different locations on the outer surface of the pipe $\left(\mathrm{P}_{\mathrm{i}}, \mathrm{i}=0,1,2,3,4\right)$ (Fig. 4) following a 0 and 180degree pattern. The method utilized to quantify the change in length was to draw straight lines of known lengths $\left(\mathrm{L}_{1}\right.$ and $\left.\mathrm{L}_{2}\right)$ along the outer surface of the pipe before the expansion process. Posterior to mechanical expansion, the length was re-measured, indicating the variation caused by the forming process. Pre- and post-expansion material properties of the tube were determined following the American Standards Testing Methods (ASTM), including (a) hardness; (b) Young's modulus; (c) yield strength; (d) ultimate tensile strengths; (e) ductility, and (f) strain at fracture.

\section{Finite Element Analysis}

The tubular expansion was modelled using commercial finite element (FEM) analysis software ABAQUS with which a 2-dimensional (2-D) axi-symmetric model (Fig. 5) was developed and compared with a more accurate, complex 3-dimensional (3-D) model. Once converged, the 2-D axi-symmetric representation was utilized as the standard simulation model during this research due to cost and computational time considerations. The tubular and mandrel geometrical parameters as well as the material properties are shown in Tables 2(a) and 2(b). As part of a logical sequence of assumptions, the authors considered the following:

(a) The tubular was modelled as a deformable body with elastic-plastic material behavior, whereas the mandrel was modelled as a rigid body; 


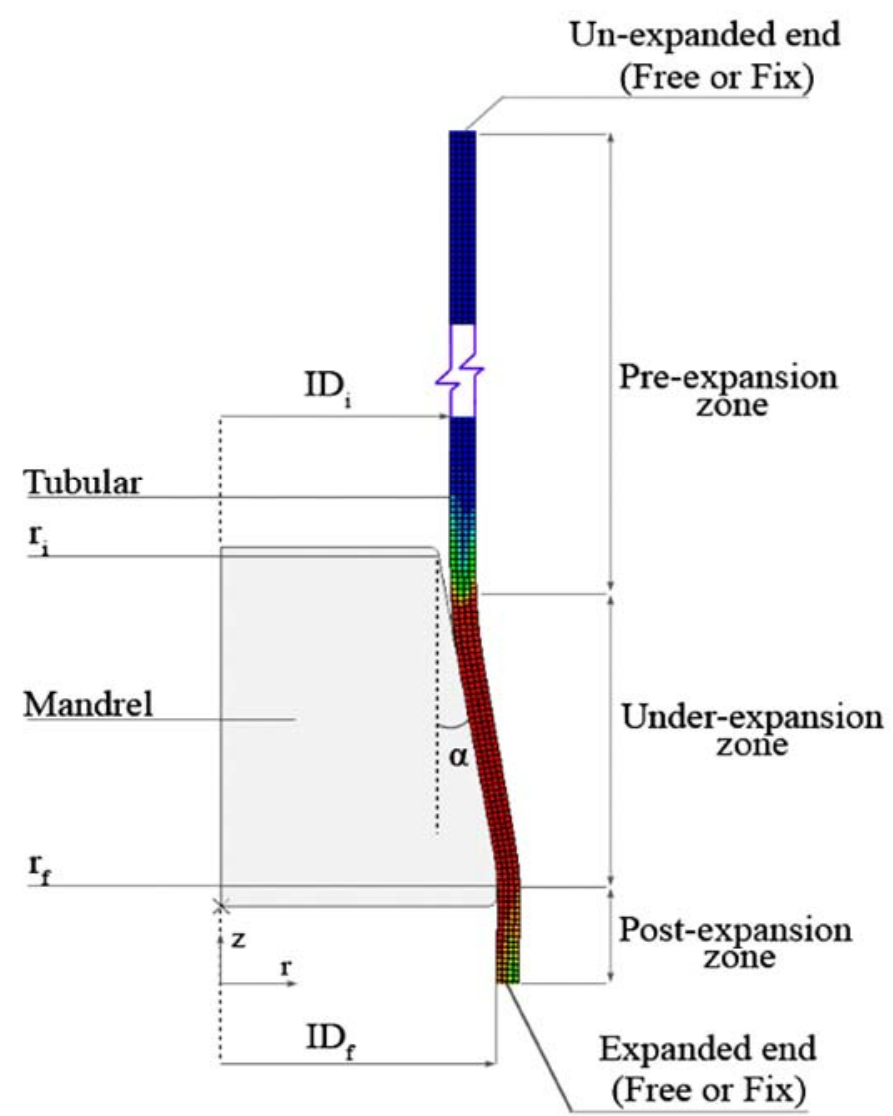

Figure 5. 2-D axi-symmetric finite element model of tubular-mandrel system (Pervez et al. 2005)

Table 2(a). Geometrical parameters for the finite element model

\begin{tabular}{lll}
\hline Part & Parameters & \multicolumn{1}{c}{ Value } \\
\hline Tubular & Outer diameter $\times$ Wall thickness $[\mathrm{mm}]$ & $193.68 \times 9.53$ \\
& & $203.20 \times 10.16$ \\
& & $203.20 \times 12.7$ \\
\multirow{3}{*}{ Mandrel } & Section length $[\mathrm{mm}]$ & 500.00 \\
& Mandrel diameter $[\mathrm{mm}]$ & $203.2 ; 209.55 ;$ \\
& & $215.9 ; 218.44$ \\
\hline
\end{tabular}

Table 2(b). Material parameters for the finite element model

\begin{tabular}{lll}
\hline Part & Para meters & \multicolumn{1}{c}{ Value } \\
\hline Tubular & Young's modulus [MPa] & 82111.00 \\
& Yield strength [MPa] & 615.23 \\
& Ultimate tensile strength [MPa] & 702.44 \\
& Poisson's ratio & 0.30 \\
MandreVTubular & Strain at fracture & 0.197 \\
\hline
\end{tabular}

(b) The von Mises yield surface was used to define the onset of plastic deformation;

(c) The hardening was assumed to be isotropic;

(d) A four-node bilinear axi-symmetric quadrilateral with reduced integration (CAX4R) elements was used to model the tubular; (e) The induced friction between the tubular and mandrel was modelled using Coulomb's law of friction;

(f) The mandrel cone angle was set at $10^{\circ}$ to compare simulation results with experimental data, whereas the edges of the cone were set at a fillet radius of 3 $\mathrm{mm}$ to avoid stress concentration. 


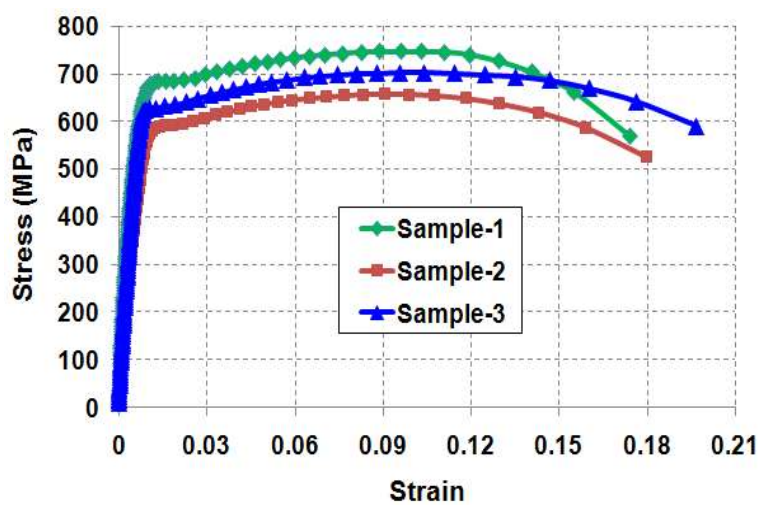

Figure 6. Stress-strain curve for as-received tabular material

The rest of the parameters, such as the force required for expansion, the contact pressure, and the wall thickness and length variations, were extracted from output database files of simulated cases. However, only results of force required to expand the tubular, reduction in wall thickness, and variation in tubular length were reported and compared with available experimental data.

In this particular case, the tubular was made of high strength, low-alloy steel with $0.23 \%$ carbon, $1.34 \%$ manganese, $0.23 \%$ silicon, $0.011 \%$ phosphorus, and $0.002 \%$ sulfur. A series of standard tests (uni-axial tensile, based on ASTM E8) were conducted to determine the mechanical properties of the as-received tubular material, resulting in a steel with high yield and ultimate tensile strengths in the range of $600 \mathrm{MPa}$ $(87,022 \mathrm{psi})$ to $620 \mathrm{MPa}(89,920 \mathrm{psi})$ and $690 \mathrm{MPa}$ (100,076 psi) to $715 \mathrm{MPa}(103,700 \mathrm{psi})$, respectively. The modulus of elasticity, and yield, ultimate, and fracture strength, and ductility and strain at fracture were measured. The stress-strain curves for three samples are shown in Fig. 6, and the average values were used in the FEM analysis. The hardening curve data required in the model were provided in the tabular form where the first pair of numbers corresponded to the initial yield stress at zero plastic strain. To simulate the various loading/boundary conditions that may occur during the conventional down-hole expansion process, the bottom end (front-end) of the tubular was held fixed while the top end (rear-end) was kept free (ie. tension). Subsequently, the bottom end was kept free while the top end was fixed (ie. compression). Ultimately, both ends were fixed.

\section{Results and Discussions}

The expansion process involves moving the mandrel from one end of the pipe to a desired location at a certain rate for a prescribed expansion ratio. This process requires that one end of the pipe must be held fixed while the other end is set either to move freely or, in the case of fixed-fixed boundary conditions, be fixed. However, these conditions have resulted in unwanted geometrical and behavioral changes of the pipe during the expansion process that may lead to premature failure of the SET during its serviceable life. A close look at the expansion process, supported by experimental data, showed that these failures may take place due to undesirable wall thickness variations during expansion. A plan to investigate the cause-andeffect of such loading/boundary conditions ended up with different scenarios that required examination to mark out and draw a conclusion on the best way of performing the expansion process. These scenarios included tension versus compression; fixed-free versus fixed-fixed boundary conditions, and mechanical expansion versus hydraulic expansion combined with either fixed-free or fixed-fixed boundary conditions. The investigation was performed following both analytical and numerical methods and using FEM, and was supported with existing experimental data.

At first, the finite element model was validated using the experimental data before employing it to study different loading/boundary conditions. Figures 7 through 9 show a comparison of results between the experimental and FEM, which were obtained from the tubular sample measuring $193.68 \mathrm{~mm} \mathrm{x} 9.53 \mathrm{~mm}$ (tubular sample a (Table 1) and using a $10^{\circ}$ mandrel with a $209.55 \mathrm{~mm}$ outer diameter (mandrel-sample 2) (Table 1)). Figure 7 shows the variation of expansion force required to push the mandrel forward inside the tubular. It was found that the expansion force required for a $20 \%$ expansion ratio obtained through the simulation coincides with experimental results, with a margin of error of less than $4 \%$. Small fluctuations in the expansion force were observed during the transient period, but overall the process was steady.

Figures 8 and 9 depict the variations in both tubular wall thickness and tubular length for a $20 \%$ expansion ratio. The tubular wall thickness were measured at ten (10) different locations before and after expansion, and an average value of wall thickness reduction was calculated for comparison with the results obtained from the simulation. Similarly, the shortening effect on the length was measured at both ends of the tested pipe. Again, the average value was calculated for comparison with the outcome of the simulation. There is an acceptable congruence between both approaches in terms of shortening of length. However, in terms of wall thickness reduction, the difference is in the vicinity of $10 \%$.

Table 3 summarizes the results obtained from both experimental and FEM analysis of tubular samples (a) and (c) in Table 1, under fixed-free and free-fixed end conditions. Mandrel sizes (1) and (3) from Table 1 were used with the above mentioned tubular sizes. Even though the results obtained from both types of analysis techniques were not exactly the same, a reasonable concordance was achieved. Therefore, the 


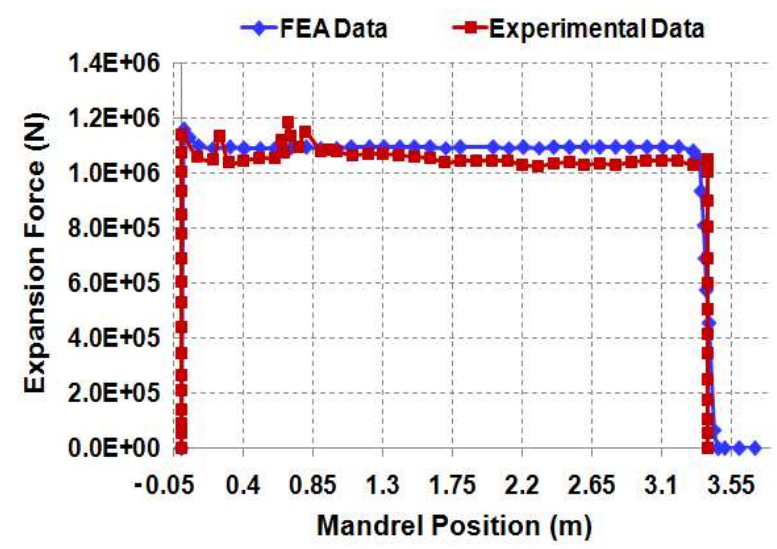

Figure 7. Variation in expansion force along tubular length (20\% expansion ratio)

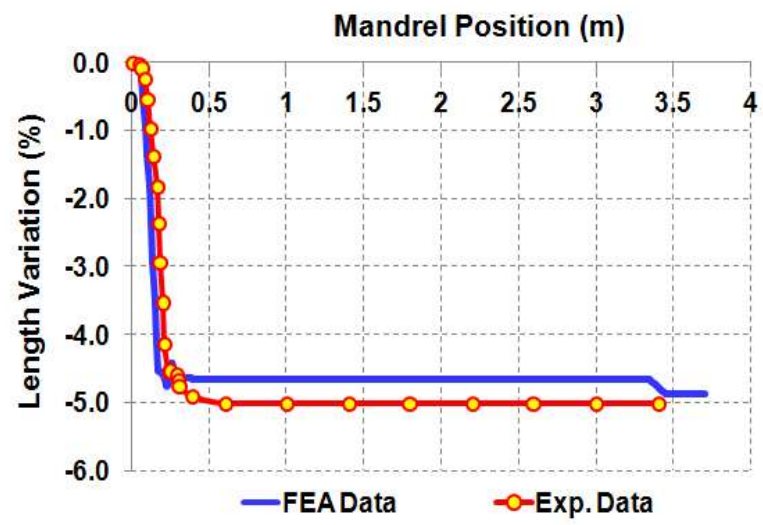

Figure 9. Length variations for a $20 \%$ expansion ratio

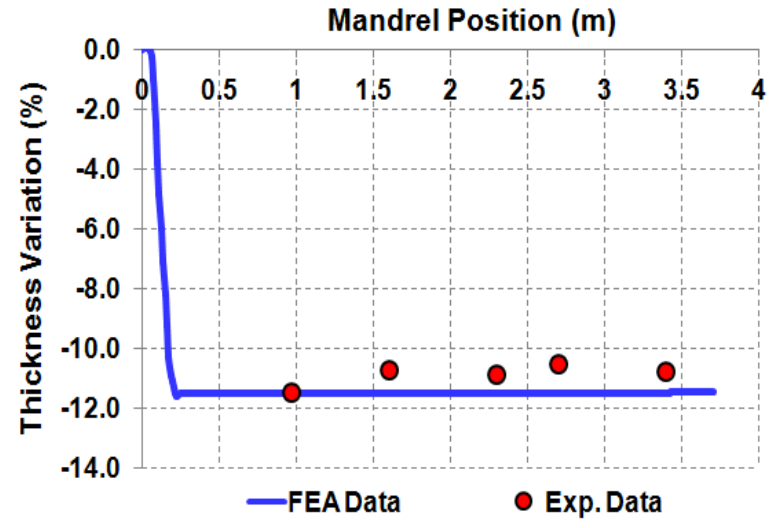

Figure 8. Thickness variations for a $20 \%$ expansion ratio

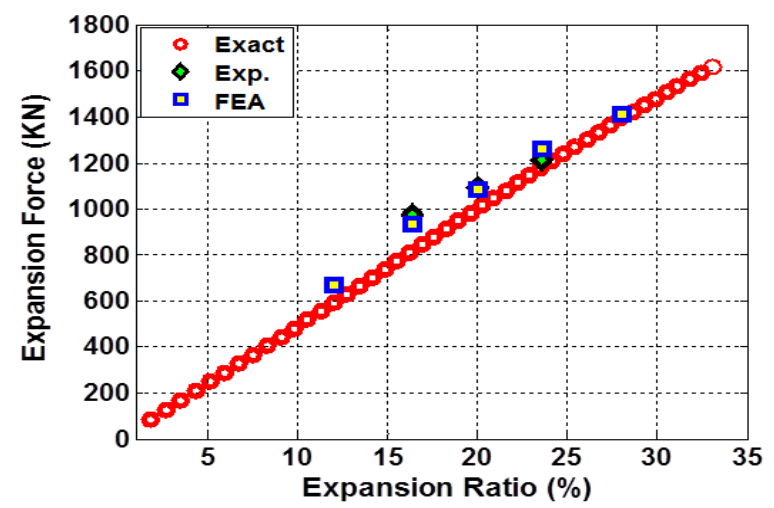

Figure 10. The variation in the expansion force with respect to the expansion ratio

Table 3. Experimental and simulation results of two tubular sizes expanded under tension and compression using mandrels of $203.2 \mathrm{~mm}$ and $215.99 \mathrm{~mm}$ diameters

\begin{tabular}{|c|c|c|c|c|c|c|c|c|}
\hline \multirow[t]{2}{*}{$\begin{array}{c}\text { Tubular } \\
\text { Specifications } \\
(\text { OD } \times \mathbf{t}) \mathrm{mm}\end{array}$} & \multirow[t]{2}{*}{$\begin{array}{l}\text { Mand rel } \\
\text { Size } \\
(\mathrm{mm})\end{array}$} & \multirow[t]{2}{*}{$\begin{array}{c}\text { End } \\
\text { Conditions }\end{array}$} & \multicolumn{2}{|c|}{$\begin{array}{c}\text { Expansio n } \\
\text { Force } \\
(k N)\end{array}$} & \multicolumn{2}{|c|}{$\begin{array}{l}\text { Length } \\
\text { Shortening } \\
(\mathrm{mm} / \mathrm{m})\end{array}$} & \multicolumn{2}{|c|}{$\begin{array}{c}\text { Wall-Thickness } \\
\text { Reduction } \\
(\%)\end{array}$} \\
\hline & & & Exp. & FEA & Exp. & FEA & Exp. & FEA \\
\hline \multirow{2}{*}{$193.68 \times 9.53$} & \multirow{2}{*}{203.2} & Fixed-Free & 1005.3 & 917.0 & 43.80 & 41.90 & 8.00 & 8.97 \\
\hline & & Free-Fixed & 972.9 & 931.0 & - & 49.02 & - & 9.01 \\
\hline \multirow{2}{*}{$203.20 \times 12.7$} & \multirow{2}{*}{215.9} & Fixed-Free & 1465.0 & 1562.6 & 49.20 & 45.00 & 11.92 & 12.30 \\
\hline & & Free-Fixed & 1550.0 & 1452.7 & - & 51.60 & 11.10 & 11.50 \\
\hline
\end{tabular}

Fixed-F ree $=$ fixed $($ mandrel end $)-$ free $($ other end $)$

Free-Fixed $=$ free $($ mandrel end $)-$ fixed (other end)

Exp. $=$ experimental results $\quad$ FEA $=$ finite element analysis results

outcome of the FEM method is acceptable, even though the discrepancy in the estimation of the shortening of the length of SET is one of the key factors for the successful field applications of this technology. From an operational point of view, positioning the expandable pipe at the planned depth inside the well- bore (either previous casing or open hole) is very difficult and consequently may be positioned somewhat higher than where it was supposed to be. Such wrong positioning of the tubular pipe without adequate information about the degree of the effect of the expansion on the length shortening would affect the anchoring of 
the fixed-end of the pipe, causing inadequate coverage of troublesome zones. However, this issue can be alleviated easily as the discrepancy is very small and such an inconsistency possibly could be mitigated by safety factors. What is interesting to note is that the difference between expanding the pipe either under tension or under compression is negligible.

A prior understanding of the forces required for expansion as well as the post-expansion characteristics such as length shortening and wall thickness variations is of critical importance for the selection of tools and the execution of the SET job in the course of designing a well. These will allow the well designers to use the appropriate tools, avoid length gaps in the overlap regions between two consecutive tubular patches, and correctly determine the post-expansion collapse and burst strengths of the pipe due to wall thickness variations. Figure 10 shows the variation in the expansion force as a function of the expansion ratio (ER) at a fixed mandrel angle of $10^{\circ}$ and a friction coefficient of 0.06 , attained for a single tubular sample size (a) (Table 1) that is expanded under fixed-free boundary conditions. It is clear from the figure that the FEM is capable of predicting the expansion force, which matches with an experimental and available semi-analytical model (Al-Abri 2011). It is important to emphasize that an increase in the expansion ratio results in an increase in the expansion force and a decrease in the tubular wall thickness and length, resulting in tubular thinning and shortening. It is obvious from Figure 10, which depicts a linear relationship, that in order to expand the pipe to $28 \%$ of its original inner diameter, a force of more than three times the one required for the $12 \%$ expansion ratio is necessary.

Table 4 summarizes experimental observations of tubular expansion processes under different loading and boundary conditions on sample (c) of Table 1 using a single size (4) mandrel as in Table 1. The investigation involves the use of mechanical pull and hydraulic push loading scenarios combined with both fixed-fixed and fixed-free boundary conditions. It is evident that the values of the force required for expansion in both mechanical and hydraulic loading scenarios are very alike for both fixed-fixed and fixed-free boundary conditions. The maximum margin of error is less than $10 \%$, whereas the maximum difference in wall thickness variation is approximately $3 \%$ under a fixed-free boundary condition and $8 \%$ for a fixedfixed boundary condition. The results suggested that expanding the tubular under a fixed-fixed boundary condition results in a larger wall thickness reduction as compared to the fixed-free condition. Thus, it is the reduction in wall thickness which will limit the maximum allowable expansion percentage of the tubular, and not the expansion force.

It is worth mentioning that, at constant yield strength and the OD of the pipe, a $10 \%$ change in the tubular wall thickness causes a reduction in the burst strength of the same magnitude when using the American Petroleum Institute (API) historical onedimension yield pressure design equation (Barlow's equation), because of the linear relationship. The effect of wall thickness reduction on the collapse rating of casing is more complex and fully related to the $\mathrm{OD} / \mathrm{t}$ ratio as well as the empirical correlation of the collapse mode. Appendix describes the design equations commonly used by well engineers when planning the casing string of a well, and how the reduction of wall thickness, along with the enlargement of the external diameter, fully affect both the internal yield and the collapse strength of the post-expansion pipe. The major effect is caused by the external-diameter-towall-thickness ratio, and the variation of nominal postexpansion yield strength produces a reasonable but less impacting effect on both design calculated values.

Two fundamental pressure limits are considered of importance in the study of pressurized cylinders. These are the internal pressure that can be withstood by a pipe at the onset of yielding of the inner surface, and the internal pressure required to cause the whole wall to yield completely. An investigation into the effect of the tubular expansion process on the pressure limits of an expanded pipe due to the effect of an inter-

Table 4. A comparison of tubular expansion under fixed-fixed and fixed-free boundary conditions using mechanical and hydraulic expansion modes

\begin{tabular}{ccccccc}
\hline $\begin{array}{c}\text { Tubular } \\
\text { Specifications } \\
(\mathbf{O D} \times \mathbf{t}) \mathbf{~ m m}\end{array}$ & $\begin{array}{c}\text { Mandrel } \\
\text { Size } \\
(\mathbf{m m})\end{array}$ & $\begin{array}{c}\text { Expansion } \\
\text { Mode }\end{array}$ & $\begin{array}{c}\text { End } \\
\text { Conditions }\end{array}$ & $\begin{array}{c}\text { Expansion } \\
\text { Force } \\
\mathbf{( k N )}\end{array}$ & $\begin{array}{c}\text { Length } \\
\text { Shortening } \\
(\mathbf{m m} / \mathbf{m})\end{array}$ & $\begin{array}{c}\text { Wall-Thickness } \\
\text { Reduction } \\
\mathbf{( \% )}\end{array}$ \\
\hline \multirow{2}{*}{$203.20 \times 10.16$} & \multirow{2}{*}{218.44} & Mydraulic & Fixed-Free & 1095.0 & 48.7 & 9.10 \\
& & Mydraulic & Fixed-Fixed & 1049.3 & $7.45^{\star}$ & 14.20 \\
& & Mechanical & Fixed-Fixed & 1150.0 & $8.00^{\star}$ & 13.11 \\
\hline
\end{tabular}

${ }^{\star}$ Amount of length recovery after relaxing the fixed-fixed boundary condition 


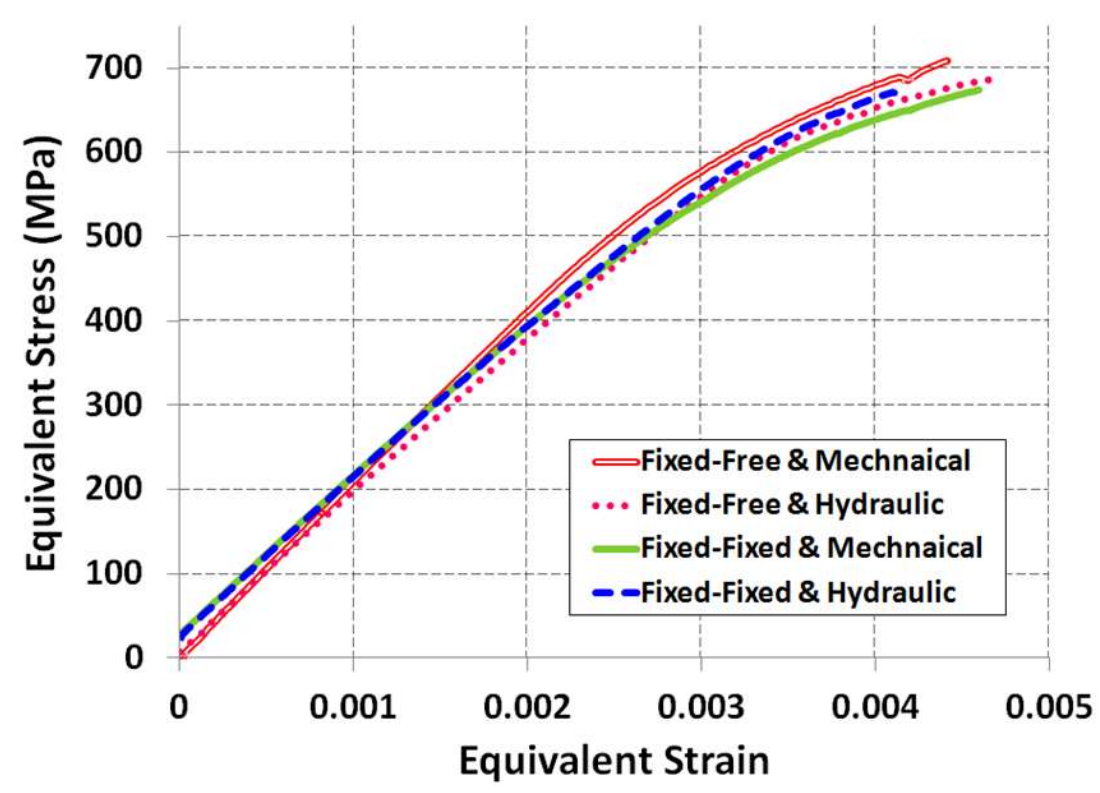

Figure 11. Stress-strain curves of four tabular samples subjected to internal pressure after they have been expanded under different conditions

nal pressure has been carried out on all reported samples (Table 4). Thus, after performing the expansion process, a tubular sample one meter in length was cut and the edges were chamfered. Afterwards, a couple of flanges were welded on both sides of the pipe, producing a chamber-type system. Finally, the proper instrumentation (strain gauges, pressure sensors, and a datalogger for data acquisition) was installed as part of the final setup. Using the recorded data of hoop and longitudinal strains, along with the internal pressure applied by a hydraulic system, the equivalent stress values were calculated. Thus, a stress-strain relationship was obtained (Fig. 11). The figure shows that the tubular samples exhibited a linear relationship at first. Then, as the internal applied pressure approaches the yield limit of the tubular pipe material, the graph starts to diverge from linearity and exhibits some hardening. However, it is vital to note that the amount of stress the post-expansion tubular sample can withstand is smaller than that of the original value of the pre-expansion material yield strength. As can also be noticed from Fig. 11, the stress-strain curve started to yield at a value that is lower than $500 \mathrm{MPa}$ as compared to the original value of the un-expanded tubular, which is larger than $600 \mathrm{MPa}$ as given in Fig. 6. Moreover, it is vital to highlight that the tubular boundary conditions have a valuable but minor effect on the internal yield limits of the pipe. However, this is an observation that is only applicable for the current tubular size and under the prescribed expansion conditions.

In order to have a better understanding of the tubular post-expansion behavior, it is essential to detail the material and mechanical characterization of expandable tubular materials. These characterizations require further mechanical testing and microscopic study as well as fracture and micro-structure evaluation, which are beyond the scope of this work and will be tackled in forthcoming investigations.

\section{Conclusions}

1. A numerical model describing the effect of different loading/boundary conditions on the tubular expansion process was developed using the finite element method. In addition, full-scale tubular expansion tests were conducted in the SQU expandable tubular test-rig to validate the numerical model.

2. The pipe's ratios of wall thickness variation to expansion, length variation to expansion, and expansion force to expansion, all obtained from the finite element model, showed good agreement with the experimental results.

3. The results obtained from the developed model as well as the calculations made by the authors using the experimental data assuming simple variation of post-expansion nominal yield strength could be used directly by well engineers to properly select expansion methods and tools to suit specific field requirements and SET casing designs.

4. Investigating the effect of loading/boundary conditions on the tubular structural integrity showed that the difference between expanding the tubular under tension and expanding it under compression is very minor and can be ignored. Furthermore, the force required for expansion in both mechanical and hydraulic loading scenarios are in good agreement with one another for both fixed-fixed and fixed-free boundary conditions with a maximum error of less than $10 \%$. 
5. The expansion of tubular samples under fixedfixed boundary condition resulted in a large thickness reduction of around $14 \%$.

6. Simple calculations using the standard casing's yield internal and collapse pressure equations suggest that the wall thickness reduction along with the enlargement of external diameter (OD/t ratio) causes a much larger and valuable effect on postexpansion burst and collapse rating than a potential variation of post-expansion nominal yield strength.

7. The effect of the tubular boundary conditions at fixed expansion ratio on the internal yield limit of an expanded tubular subjected to an internal pressure was carried out. It was found that the boundary conditions had a very minor effect on the yield limit of the tubular. This observation was also asserted by the calculation done using an API yield pressure design equation.

\section{Acknowledgments}

The authors would like to thank SQU and PDO for their financial support throughout the research. Useful discussion with Professor Tasneem Pervez and members of the Applied Mechanics and Advanced Materials Research Group (AM ${ }^{2} \mathrm{RG}$ ) is highly appreciated. All the experimental work was done with the assistance of Dr. Siegfried Trautwein and Mr. Ahmed S. Faiz.

\section{References}

Akisanya AR, Khan FU, Deans WF, Wood P (2011), Cold hydraulic expansion of oil well tubulars. International Journal of Pressure Vessel and Piping 88(11-12):465-472.

Al-Abri OS (2011) Analytical and numerical solution for large plastic deformation of solid expandable tubular. SPE paper \# 152370. SPE International Student paper contest at the SPE Annual Technical Conference and Exhibition, 30 October to 2 November 2011, Denver, Colorado, USA.

BinAli A, Baggal Z, Mumen A, Aubed Y (2009), Utilizing expandable casing clad enabled short radius sidetrack in wells with casing leaks. SPE paper \#126050, 9 May 2009, Society of Petroleum Engineers, Saudi Arabia.

Binggui X, Yanping Z, Hui W, Hongwei Y, Tao J (2009), Application of numerical simulation in the solid expandable tubular repair for casing damaged wells. Petroleum Exploration and Development 36(5):651-657.

Cales J, Shepherd D, Wiest B, York PL, Daigle C, Rose L, Patterson M (2001), Subsidence remediation-extending well life through the use of solid expandable casing systems. American Association of Drilling Engineers (AADE), 27-29
May 2001, Houston Chapter Conference, Houston, USA.

Cales J (2003), The development and applications of solid expandable tubular technology. Paper \#2003-136. Petroleum Society's Canadian International Petroleum Conference, Calgary, Canada, June 10-13.

Campo D, Williams C, Filippov A, Cook L, Brisco D, Dean B, Ring L (2003), Monodiameter drilling liner-from concept to reality. SPE paper \# 79790. SPE Drilling Conference, Amesterdam, The Netherlands, 19-21 February.

Carstens C, Strittmatter K (2006), Solid Expandable Tubular Technology: The value of planned installations vs. contingencies. Journal of SPE Drilling and Completion 21(4):279-286.

Dupal K, Campo DB, Andrews CJ, Cook RL, Ring LM, York PL (2002), Realization of the monodiameter well: Evolution of game changing technology. OTC paper \# 14312, 6-9 May 2002, Offshore Technology Conference, Houston, USA.

Filippov A, Mack R, Cook L, York P, Ring L, McCoy T (1999), Expandable tubular solutions. SPE paper \# 56500, 3-6 October 1999, SPE Annual Technical Conference and Exhibition, Houston, Texas, USA.

ISO/TR 10400. Petroelum and natural gas industriesEquations and calculations for the properties of casing, tubing, drill pipe and line pipe used as casing or tubing, first edition. 15 December 2007.

Jabs M (2004), Using Expandable Metal Technology to Create a Monobore Well. Paper OTC \# 16670, 3-6 May 2004, Offshore Technology Conference, Houston, Texas, USA.

Karrech A, Seibi AC (2010), Analytical model for the expansion of tubes under tension. Journal of Materials Processing Technology 210(2):356-362.

Mack RD (2005), The effect of tubular expansion on the mechanical properties and performance of selected OCTG-results of laboratory studies. OTC paper \# 17622, 2-5 May 2005, Offshore Technology Conference, Houston, USA.

Mack RD, McCoy T, Ring L (1999), How in-situ expansion affects casing and tubing properties. World Oil, July 1999, 69-71.

Pervez T (2010), Experimental and numerical investigations of expandable tubular structural integrity for well applications. Journal of Achievements in Materials and Manufacturing Engineering 41(12):147-154.

Pervez T, Al-Hiddabi S, Al-Houqani S, Al-Jahwari FK, Marketz F, Qamar SZ, Velden M (2011), Tubular expansion in irregularly shaped boreholes-Computer simulation and field measurement. Journal of Petroleum Science and Engineering 29(7):735-744. 
Pervez T, , Al-Abri OS, Khan R, Qamar SZ (2012), Experimental and numerical simulation of in-situ tube expansion for deep gas wells. Materials and Manufacturing Processes 27(7):727-732.

Pervez T, Al-Jahwari FK, Qamar SZ, Seibi AC (2008), Use of SET in cased and open holes: Comparison between aluminum and steel. Journal of Materials and Design 29(4):811-817.

Pervez T, Karrech A, Seibi AC (2005), Simulation of solid tubular expansion in well drilling using finite element method. Journal of Petroleum Science and Technology 23(7-8):775-794.

Pervez T, Karrech A, Seibi AC (2006), Analytical solution for wave propagation due to pop-out phenomenon in solid expandable tubular system. Journal of Petroleum Science and Technology 24(8):923-942.

Seibi AC, Al-Hiddabi SA, Pervez T (2005), Structural behavior of solid tubular expansion under large plastic deformation. ASME Journal of Energy Resources \& Technology 127(4):323-326.
Seibi AC, Karrech A, Pervez T (2007), Post-expansion tube response under mechanical and hydraulic expansion-A comparative study. Journal of Pressure Vessels Technology, ASME Transaction 129(1):118-124.

Seibi AC, Al-Hiddabi SA, Al-Yhamadi A, Al-Shabibi A, Karrech A, Pervez T (2009), Dynamic effects of mandrel/tubular interaction on downhole solid tubular expansion in well engineering. Journal of Energy Resources Technology Transactions ASME 131(1):013101-013108.

Seibi AC, Al-Hiddabi SA, Karrech A, Pervez T (2006), Coupled stress and pressure waves propagation in an elastic solid tube submerged in fluids. Journal of Energy Resource Technology, ASME Transaction Vol. 128(4):247-256.

Stewart RB, Lohbeck WCM, Marketz F (1999), Expandable wellbore tubular. SPE paper \# 6076, 16 Oct 1999, SPE Technical Symposium, Dhahran, Saudi Arabia, October. 


\section{Appendix}

The nominal internal pressure rating (ie. burst rating) of conventional casing pipe is calculated by using the historical API equation or Barlow Equation. This equation is one-dimensional representation of the von Mises condition in association with a fairly accurate expression of the hoop stress in the pipe body. The Barlow's equation, which is less accurate than Lame's for thin wall pipe and neglects the axial stress, approximates the hoop stress to match it with the yield strength of the pipe body. In other words, the initial yield pressure of a thin pipe body $\mathrm{P}_{i Y-A P I}$ is defined as:

$$
P_{i Y-A P I}=\frac{0.875\left(2 \sigma_{\text {Yield }}\right) t}{D}
$$

where $\sigma_{\text {Yield }}$ is the minimum nominal yield strength, $t$ is the pipe wall thickness, $D$ is the pipe diameter, and 0.875 is the factor to account the manufacturing tolerance of the pipe wall specified by API standards.

Current tendencies within the industry suggest that the most accurate calculation method of the designed yield pressure of conventional oil and gas tubulars (casing, for instance) is through the criterion proposed by von Mises. The triaxial pipe body yield combines a diverse number of equations, such a Lame's for thick cylinder, Timoshenko's for bending stress, as well as uniform axial stress (independent from bending) and torsional shear stress. The equation is as follows:

$$
\sigma_{\text {vonMises }}=\sqrt{\sigma_{r}^{2}+\sigma_{h}^{2}+\left(\sigma_{a}+\sigma_{b}\right)^{2}-\sigma_{r} \sigma_{h}-\sigma_{r}\left(\sigma_{a}+\sigma_{b}\right)-\sigma_{h}\left(\sigma_{a}+\sigma_{b}\right)+3 \tau_{h a}^{2}}
$$

where $\sigma_{\text {vonMises }}$ is the equivalent von Mises stress (initial yield pressure), $\sigma_{a}$ is the component of axial stress not due to bending, $\sigma_{b}$ is the component of the axial stress due to bending, $\sigma_{h}$ is the hoop stress, $\sigma_{r}$ is the radial stress, and $\tau_{h a}$ is the torsional stress.

Based upon the triaxial principle, the initial yield of the pipe body occurs when the stress applied in its working environment reaches the equivalent von Mises stress, and the elastic behavior of the pipe never is exceeded (recommended condition) when the applied stress is always lower than such initial yield point. For the special case of purely internal pressure, when external pressure, axial load, bending and torsion are zero, the internal pressure at yield for an open-end thick pipe is:

$$
P_{i Y I}=\frac{\sigma_{\text {yield }}\left(D^{2}-d_{\text {wall }}^{2}\right)}{\sqrt{3 D^{4}+d_{\text {wall }}^{4}}}
$$

where $d_{\text {wall }}=D-2(0.875) t, D$ is specified outside pipe diameter and $t$ is the wall thickness.

In terms of collapse strength, for L80 material for instance, the $D / t$ value of pre-expansion pipe corresponds to the range for plastic collapse (Table 6, ISO 10400). However, once the tubular is expanded both $D$ and $t$ are notably modified to the point where, by assuming the same conventional material yield strength $\sigma_{\text {yield }}$ of 80,000 psi, the collapse behavior becomes transitional (Table 7, ISO 10400). Nevertheless, unpublished data suggests that even the $\sigma_{\text {yield }}$ is also different after expansion, mainly due to the cold work process. In order to protect further reports, the authors assumed that the variation of $\sigma_{\text {yield }}$ ranges from $-15 \%$ to $+15 \%$. In consequence, $\sigma_{\text {yield }}$ ranges from $68 \mathrm{k}$ to $92 \mathrm{k}$ psi; transforming the new SET material into either a potential C70 (equivalent: $\mathrm{C} 75$ ) or C90 material (nomenclature used by ISO 10400). In both cases, the collapse equation corresponds to the transition zone; but the nominal minimum yield strength varies and affects both the overall collapse and burst pressure calculations.

Based on the above, the collapse pressure rating of pre-expansion SET is calculated by using the plastic collapse pressure equation suggested by ISO 10400. However, the obtained value is irrelevant to well engineers because the pipe is not suitable as casing string during its initial pre-expansion condition. On the other hand, the after-expansion properties of the tubular must be suitable to withstand all loads during different stages of the drilling, installation and production processes. Consequently, both the internal pressure/yield and the collapse pressure must be calculated using the post-expansion dimensions and final minimum yield strength.

Tables A-1 and A-2 shows both dimensions and mechanical properties (internal yield and collapse pressure) of the SET sample (c) from Table 1 after expansion, which result in 17.2\% OD enlargement (using mandrel of $215.9 \mathrm{~mm}$ diameter, $8.5 \mathrm{in})$; wall thickness reduction of $12.3 \%\left(t_{\text {after expansion }}=0.5 * 0.877=0.439 \mathrm{in}\right)$, and assuming yield strength variation in the magnitude of $\pm 15 \%$. The final dimensions before and after expansion of the selected SET sample is as follows: 
Table A-1. Dimension of sample (c) from Table 1, pre and post expansion

\begin{tabular}{cccc}
\hline SET Dimension & $\begin{array}{c}\text { Pre- } \\
\text { Expansion }\end{array}$ & $\begin{array}{c}\text { Enlargement (+) or } \\
\text { Reduction (-); } \\
\text { Percentage }\end{array}$ & $\begin{array}{c}\text { Post- } \\
\text { Expansion }\end{array}$ \\
\hline External Diameter; mm (in) & $203.20(8.00)$ & $+17.2 \%$ & $238.18(9.377)$ \\
Internal Diameter; mm (in) & $177.80(7.00)$ & $+21.4 \%$ & $215.90(8.50)$ \\
Wall Thickness; mm (in) & $12.70(0.50)$ & $-8.8 \%$ & $11.15(0.439)$ \\
\hline
\end{tabular}

Now, using the geometrical variation of the SET sample provided in Table A-1 with the aid of the standard API formulations given by equations (1) to (3), comparison to standard ISO-API casing sizes and materials was performed as follows:

Table A-2. Yield internal and collapse strength of post-expansion condition of sample in Table A-1; using standard ISO-10400 design equations

\begin{tabular}{|c|c|c|c|c|c|c|c|c|c|c|}
\hline \multirow{2}{*}{$\begin{array}{c}\text { Equivalent API- } \\
\text { Casings \& SET } \\
\text { Sizes }\end{array}$} & \multirow{2}{*}{$\begin{array}{l}\text { OD } \\
\text { (in) }\end{array}$} & \multirow{2}{*}{$\begin{array}{c}\mathbf{t} \\
\text { (in) }\end{array}$} & \multirow{2}{*}{$\mathbf{O D} / \mathbf{t}$} & \multirow{2}{*}{$\begin{array}{c}\text { Min. } \\
\text { Yield } \\
\text { Strength } \\
\text { (Psi) }\end{array}$} & \multicolumn{3}{|c|}{ Internal Pressure/Yield (Psi) } & \multicolumn{3}{|c|}{ Collapse Pressure (Psi) } \\
\hline & & & & & $\begin{array}{l}\text { Nominal } \\
\text { API }\end{array}$ & $\begin{array}{c}\text { Calculated } \\
\text { Historical } \\
\text { Equation }\end{array}$ & $\begin{array}{c}\text { Calculated } \\
\text { Triaxial } \\
\text { Equation }\end{array}$ & $\begin{array}{c}\text { Nominal } \\
\text { API }\end{array}$ & $\begin{array}{l}\text { Calculated } \\
\text { Plastic } \\
\text { Equation }\end{array}$ & $\begin{array}{c}\text { Calculated } \\
\text { Transition } \\
\text { Equation }\end{array}$ \\
\hline API 7-5/8, 39\# L80 & 7.625 & 0.500 & 15.25 & 80,000 & 9,180 & 9,180 & 9,104 & 8,820 & 8,819 & - \\
\hline API 8-5/8, 44\# L80 & 8.625 & 0.500 & 17.25 & 80,000 & 8,120 & 8,116 & 8,063 & 6,950 & 6,951 & - \\
\hline API9-5/8, 43.5\# L80 & 9.625 & 0.435 & 22.13 & 80,000 & 6,330 & 6,327 & 6,302 & 3,810 & 3,812 & - \\
\hline API9-5/8, 43.5\# C75 & 9.625 & 0.435 & 22.13 & 75,000 & 5,930 & 5,932 & 5,908 & 3,730 & 3,731 & - \\
\hline API9-5/8, 43.5\# C90 & 9.625 & 0.435 & 22.13 & 90,000 & 7,120 & 7,118 & 7,090 & 4,010 & - & 4,010 \\
\hline \multicolumn{11}{|c|}{ PRE-EXPANSION: SET Sample $203.2 \mathrm{~mm} \times 12.7 \mathrm{~mm}$} \\
\hline SET LX-80/LSX-80 & 8.000 & 0.500 & 16.00 & 80,000 & - & 8,750 & 8,684 & - & 8,064 & - \\
\hline \multicolumn{11}{|c|}{ POST-EXPANSION: SET Using 12.3\% Thickness Reduction on Same Sample (203.2mm x 12.7mm) } \\
\hline \multirow{2}{*}{ SET LX-80/LSX-80 } & 9.377 & 0.439 & 21.36 & 68,000 & - & 5,571 & 5,548 & - & 3,939 & - \\
\hline & 9.377 & 0.439 & 21.36 & 92,000 & - & 7,537 & 7,506 & - & 4,428 & - \\
\hline
\end{tabular}

In order to add a complete analysis of the effect of wall thickness and diameter enlargement of all post-expansion samples, the authors suggest the following data: (a) Table A-3 to describe the main yield internal and collapse rating of pre-expansion SET sample, and (b) Table A-4 to describe the full effect of $D / t$ changes on burst and collapse design calculations. From Table A-4; which shows a realistic design calculation used by well engineers during the casing design phase of the SET installation job, it is evident that the major effect on SET pipe burst and collapse rating is generated by the $D / t$ ratio, in a larger magnitude than the variation of the nominal yield strength. Similar conclusions are obtained by the unpublished data provided by manufacturer as a result of physical collapse tests conducted on only one set of samples. A much larger discussion will be presented to readers in further papers.

Table A-3. As received conditions of SET samples and yield internal and collapse strength pre-expansion.

\begin{tabular}{|c|c|c|c|c|c|c|c|c|c|}
\hline \multirow{2}{*}{$\begin{array}{l}\text { OD } \\
\text { (in) }\end{array}$} & \multirow{2}{*}{$\begin{array}{l}\mathbf{t} \\
\text { (in) }\end{array}$} & \multirow{2}{*}{$\begin{array}{c}\boldsymbol{\sigma}_{\mathbf{y}} \\
\text { (Psi) }\end{array}$} & \multirow[t]{2}{*}{$\mathbf{O D} / \mathbf{t}$} & \multicolumn{3}{|c|}{ Internal Press ure/Yield (Psi) } & \multicolumn{3}{|c|}{ Collapse Pressure (Psi) } \\
\hline & & & & $\begin{array}{c}\text { Nominal } \\
\text { API }\end{array}$ & $\begin{array}{l}\text { Calculated } \\
\text { Historical } \\
\text { Equation }\end{array}$ & $\begin{array}{c}\text { Calculated } \\
\text { Triaxial } \\
\text { Equation }\end{array}$ & $\begin{array}{c}\text { Nominal } \\
\text { API }\end{array}$ & $\begin{array}{l}\text { Calculated } \\
\text { Plastic } \\
\text { Equation }\end{array}$ & $\begin{array}{l}\text { Calculated } \\
\text { Transition } \\
\text { Equation }\end{array}$ \\
\hline 7.625 & 0.375 & 80,000 & 20.33 & 6890.00 & 6885.25 & 6853.01 & 4790.00 & 4788.77 & - \\
\hline 8.000 & 0.400 & 80,000 & 20.00 & - & 7000.00 & 6966.12 & - & 4990.13 & - \\
\hline 8.000 & 0.500 & 80,000 & 16.00 & - & 8750.00 & 8683.78 & - & 8060.88 & - \\
\hline
\end{tabular}


Table A-4. Post-expansion yield internal and collapse strength of all tested samples, assuming variation of yield strength $( \pm 15 \%)$; based on standard ISO-10400 design equations

\begin{tabular}{|c|c|c|c|c|c|c|c|c|c|c|c|c|c|c|c|}
\hline \multicolumn{3}{|c|}{ Pre-expansion } & \multirow{3}{*}{$\begin{array}{l}\text { Mandrel } \\
\text { Size } \\
\text { (in) }\end{array}$} & \multirow{3}{*}{$\begin{array}{c}\text { Exp. } \\
\text { Ratio } \\
(\%)\end{array}$} & \multirow{3}{*}{ BCs } & \multirow{3}{*}{$\begin{array}{l}\Delta \mathbf{t} \\
(\%)\end{array}$} & \multicolumn{9}{|c|}{ Post-expansion } \\
\hline \multirow{2}{*}{$\begin{array}{l}\text { OD } \\
\text { (in) }\end{array}$} & \multirow{2}{*}{$\begin{array}{c}\mathbf{t} \\
\text { (in) }\end{array}$} & \multirow{2}{*}{$\begin{array}{c}\boldsymbol{\sigma}_{\mathbf{y}} \\
(\mathrm{K} \mathrm{psi})\end{array}$} & & & & & $\sigma_{\mathbf{y}}$ & & $t_{\exp }$ & OD & $O D / t_{\text {exp }}$ & $\begin{array}{r}\text { Internal Pr } \\
(\mathrm{P} \\
\end{array}$ & $\begin{array}{l}\text { ssur e/Yield } \\
\text { i) }\end{array}$ & $\begin{array}{r}\text { Collapse } \\
(\mathrm{P} \\
\end{array}$ & $\begin{array}{l}\text { Pressure } \\
\text { i) }\end{array}$ \\
\hline & & & & & & & (K ps i) & (in) & (in) & (in) & & $\begin{array}{l}\text { Calculated } \\
\text { Historical } \\
\text { Equation }\end{array}$ & $\begin{array}{c}\text { Calculated } \\
\text { Triaxial } \\
\text { Equation }\end{array}$ & $\begin{array}{l}\text { Calculated } \\
\text { Plastic } \\
\text { Equation }\end{array}$ & $\begin{array}{l}\text { Calculated } \\
\text { Transition } \\
\text { Equation }\end{array}$ \\
\hline \multirow{8}{*}{7.625} & \multirow{8}{*}{0.375} & \multirow{8}{*}{80} & \multirow{4}{*}{8.00} & \multirow{4}{*}{1636} & \multirow{2}{*}{ Fix-Free } & \multirow{2}{*}{6.40} & 68 & 8.000 & 0.351 & 8.702 & 24.79 & 4800 & 4785 & - & 2741 \\
\hline & & & & & & & 92 & 8.000 & 0.351 & 8.702 & 24.79 & 6494 & 6474 & - & 3153 \\
\hline & & & & & \multirow{2}{*}{ Fix-Fix } & \multirow{2}{*}{8.55} & 68 & 8.000 & 0.343 & 8.686 & 25.33 & 4698 & 4684 & - & 2626 \\
\hline & & & & & & & 92 & 8.000 & 0.343 & 8.686 & 25.33 & 6357 & 6337 & - & 2995 \\
\hline & & & \multirow{2}{*}{825} & \multirow{2}{*}{20.00} & \multirow{2}{*}{ Fix-Free } & \multirow{2}{*}{1030} & 68 & 8.250 & 0.336 & 8.923 & 26.53 & 4486 & 4474 & - & 2385 \\
\hline & & & & & & & 92 & 8.250 & 0.336 & 8.923 & 26.53 & 6069 & 6053 & - & 2663 \\
\hline & & & \multirow{2}{*}{8.50} & \multirow{2}{*}{23.64} & \multirow{2}{*}{ Fix-Free } & \multirow{2}{*}{13.16} & 68 & 8.500 & 0.326 & 9.151 & 28.10 & 4235 & 4224 & - & 2100 \\
\hline & & & & & & & 92 & 8.500 & 0.326 & 9.151 & 28.10 & 5729 & 5715 & - & 2270 \\
\hline \multirow{4}{*}{8.000} & \multirow{4}{*}{0.400} & \multirow{4}{*}{80} & \multirow{4}{*}{8.60} & \multirow{4}{*}{19.40} & \multirow{2}{*}{ Fix-Free } & 884 & 68 & 8.600 & 0.365 & 9.329 & 25.58 & 4651 & 4637 & - & 3026 \\
\hline & & & & & & 0.04 & 92 & 8.600 & 0.365 & 9.329 & 25.58 & 6293 & 6274 & - & 2540 \\
\hline & & & & & & & 68 & 8.600 & 0.345 & 9.290 & 26.91 & 4422 & 4410 & - & 2721 \\
\hline & & & & & FIX-FIX & 13.69 & 92 & 8.600 & 0.345 & 9.290 & 26.91 & 5983 & 5967 & - & 2229 \\
\hline & & & & & & & 68 & 8.000 & 0.455 & 8.909 & 19.60 & 6071 & 6040 & 4793 & - \\
\hline & & & 8.00 & 1430 & Fix-Free & 9.10 & 92 & 8.000 & 0.455 & 8.909 & 19.60 & 8214 & 8172 & 5602 & - \\
\hline 8.000 & 0.500 & 80 & & & & & 68 & 8.500 & 0.440 & 9.381 & 21.30 & 5587 & 5563 & 3955 & - \\
\hline & & & 8.50 & 21.40 & Fix-Free & 11.92 & 92 & 8.500 & 0.440 & 9.381 & 21.30 & 7558 & 7526 & 4436 & - \\
\hline
\end{tabular}

